\title{
Position-controlled [100] InP nanowire arrays
}

\author{
Jia Wang, ${ }^{1}$ Sébastien Plissard, ${ }^{1}$ Moïra Hocevar, ${ }^{2}$ Thuy T. T. Vu, ${ }^{1}$ Tilman Zehender, ${ }^{1}$ \\ George G. W. Immink, ${ }^{3}$ Marcel A. Verheijen, ${ }^{1,3}$ Jos Haverkort, ${ }^{1}$ \\ and Erik P. A. M. Bakkers ${ }^{1,2, a)}$ \\ ${ }^{1}$ Department of Applied Physics, Eindhoven University of Technology, P.O. Box 513, 5600 MB Eindhoven, \\ The Netherlands \\ ${ }^{2}$ Kavli Institute of Nanoscience, Delft University of Technology, 2628CJ Delft, The Netherlands \\ ${ }^{3}$ Philips Innovation Services Eindhoven, High Tech Campus 11, 5656AE Eindhoven, The Netherlands
}

(Received 25 November 2011; accepted 4 January 2012; published online 30 January 2012)

\begin{abstract}
We investigate the growth of vertically standing [100] zincblende InP nanowire (NW) arrays on InP (100) substrates in the vapor-liquid-solid growth mode using low-pressure metal-organic vapor-phase epitaxy. Precise positioning of these NWs is demonstrated by electron beam lithography. The vertical NW yield can be controlled by different parameters. A maximum yield of $56 \%$ is obtained and the tapering caused by lateral growth can be prevented by in situ $\mathrm{HCl}$ etching. Scanning electron microscopy, high-resolution transmission electron microscopy, and micro-photoluminescence have been used to investigate the NW properties. (C) 2012 American Institute of Physics. [doi:10.1063/1.3679136]
\end{abstract}

Indium phosphide (InP) nanowires (NWs) have attracted an increasing amount of attention because of their extensive use in electronics, ${ }^{1}$ optoelectronics, ${ }^{2,3}$ and photovoltaics, ${ }^{4-6}$ and both axial ${ }^{7,8}$ and core-shell ${ }^{9}$ heterostructures have been developed for new advanced nanoscale devices. However, most NWs reported are grown in the direction perpendicular to that of the close-packed planes in the crystal structure, i.e., in the $\langle 111\rangle$ direction for zincblende (ZB) or the $\langle 0001\rangle$ direction for wurtzite (WZ), in which the NWs commonly have planar stacking faults (SFs), leading to a faulted crystal or even a mixture of $\mathrm{ZB} / \mathrm{WZ}$ crystal structures. ${ }^{10-15}$ Although SFs have been found to contribute to many phenomena, ${ }^{12,15}$ they could significantly affect the electronic and optical properties ${ }^{13,16-19}$ of nanowires. Zincblende nanowire growth in the $\langle 100\rangle$ direction, which has seldom been reported for $\mathrm{InP},{ }^{20}$ is of particular interest since such wires are inherently free from SFs and represents an ideal ZB single crystal. However, a systematic study of InP nanowires grown on InP (100) substrates with precise control of the position is still challenging and has not been reported yet.

In this work, we report on the growth of [100] ZB InP NWs by the vapor-liquid-solid (VLS) growth mechanism ${ }^{21}$ catalyzed by $\mathrm{Au}$ and using low-pressure $(50 \mathrm{mbar})$ metalorganic vapor phase epitaxy (MOVPE) on Sn-doped InP (100) substrates; this orientation has been mostly used in device applications. Electron beam lithography (EBL) is used to position the NWs since future device applications in optics as well as electronics require precise site control. Note that nano-imprint has been demonstrated to enable position control at the wafer level. ${ }^{22} \mathrm{We}$ demonstrate that the vertical NW growth direction on a (100) substrate depends strongly on parameters such as growth temperature, nanowire diameter, V/III ratio, and precursor molar fraction. In situ $\mathrm{HCl}$ etching is used to prevent lateral growth and to realize diameter uniformity along the NW axial direction. ${ }^{23}$ Finally, we demonstrate control of position, diameter, length, yield, and

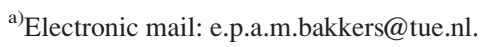

tapering of defect-free pure zincblende [100] NW grown on InP (001) substrates.

The as-grown samples were studied using scanning electron microscopy (SEM) and transmission electron microscopy (TEM). For micro-photoluminescence (PL) measurements, the NWs were transferred to a thermally oxidized Si wafer. The micro-PL measurements were carried out at $4 \mathrm{~K}$ using a $100 \times$ long distance objective. A diode laser (635 nm line) was used as excitation source, and the PL was detected by a cooled CCD detector.

In Figs. 1(a) and 1(b), SEM images of one NW field grown at $460{ }^{\circ} \mathrm{C}$ are shown. More than half of the e-beam defined $\mathrm{Au}$ particles grow into vertical [100] NWs (yield $=352 / 625=56.32 \%$ ). As can be seen in close-up (Figs. 1(c) and 1(d)), all vertical NWs have a rectangular cross-sectional shape, similar to that in Ref. 20. The nature of the side facets was determined in two independent manners: (1) top-view SEM imaging, having the edges of the substrate for reference of the crystallographic orientation. (2) Using TEM, by a combination of electron diffraction and subsequent STEM/HAADF imaging to determine the brightness profile across the nanowire. Directly below the gold particle, an octagonal shape is present formed by four $\{110\}$ and four $\{100\}$ side facets. Further down the nanowire, lateral growth results in a morphology characterized by four $\{100\}$ side facets instead of four $\{110\}$ side facets as reported before. ${ }^{20}$ These four $\{100\}$ side facets are observed at most growth conditions. While at low V/III ratios $(<160)$, four nonparallel (110) side facets are formed, and the nanowires maintain a quasi-octagonal cross-section. We argue that the P-terminated $\{100\}$ facets are stabilized by the high V/III ratio. For the non-vertical wires, 3 different types of inplane NW orientations can be found as shown by the marked wires in Fig. 1(b). The growth direction marked with 1 corresponds to growth in a $\langle 111\rangle \mathrm{B}$ direction. The other two growth directions can be explained by a change in growth direction after a rotational twin boundary; NWs marked 2 and 3 grow in new $\langle 100\rangle$ and $\langle 111\rangle$ directions after this twin, 
(a)

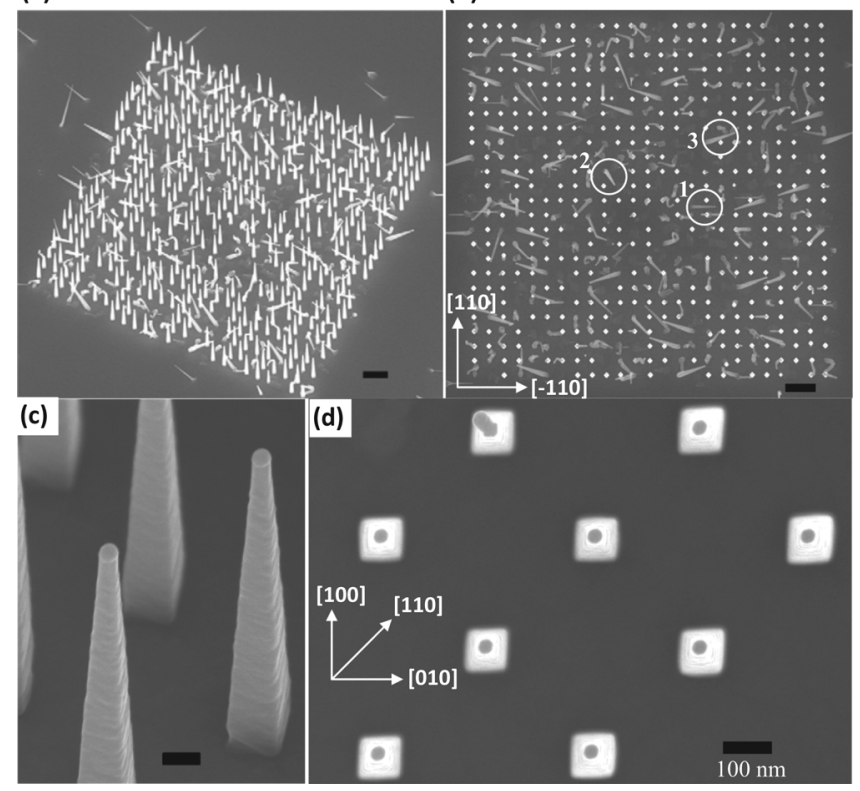

FIG. 1. SEM images of as-grown InP NW arrays on a InP (100) substrate with $\mathrm{Au}$ diameters $\left(\mathrm{D}_{\mathrm{Au}}\right)=50 \mathrm{~nm}$, pitch $=500 \mathrm{~nm}$, growth temperatures $(\mathrm{T})=460{ }^{\circ} \mathrm{C}, \mathrm{V} / \mathrm{III}$ ratio $=229$, and standard total molar fraction $\left(\mathrm{F}_{\text {total }}\right)$. (a), (c) View on a substrate tilted by $40^{\circ}$. (b), (d) Top-view images showing the square shape of vertical NWs with $\{100\}$ side facets. Circular marks in (b) show three different tilted growth directions. The scale bar is $1 \mu \mathrm{m}$ for (a), (b) and $100 \mathrm{~nm}$ for (c), (d).

respectively. For type 2 and 3, the four in-plane directions are $45^{\circ}$ and $70^{\circ}$ off [110], respectively, and the angles with the surface normal are $20^{\circ}$ and $72^{\circ}$, respectively. The further details of the different growth directions are out of the scope of this paper.

For each sample, the yield of more than $3 \mathrm{NW}$ fields (each containing $625 \mathrm{NWs}$ ) from different areas over the wafer was measured by using SEM. The yield is strongly affected by the growth temperature as can be seen in Fig. 2(a). Here, patterned $\mathrm{Au}$ island diameters $\left(\mathrm{D}_{\mathrm{Au}}\right)=50 \mathrm{~nm}$, $\mathrm{V} / \mathrm{III}$ ratio $=229$, and standard precursor molar fractions $\left(\mathrm{F}_{\mathrm{TMI}}=3.8 \times 10^{-5}\right.$ and $\left.\mathrm{F}_{\mathrm{PH} 3}=5.5 \times 10^{-3}\right)$ are used. At too low $\left(380^{\circ} \mathrm{C}\right)$ or too high $\left(480^{\circ} \mathrm{C}\right)$ temperatures $\mathrm{NWs}$ do not grow at all. At $400{ }^{\circ} \mathrm{C}$ almost all wires are grown in tilted directions. Vertically [100]-oriented wires were found in the range $420-460{ }^{\circ} \mathrm{C}$ with a maximum at $460{ }^{\circ} \mathrm{C}$. We find an optimum temperature for vertical growth above the Au-In eutectic temperature $\left(\mathrm{T}=454^{\circ} \mathrm{C}\right)$. Though the sample temperature is higher than $454^{\circ} \mathrm{C}$, vertical NW growth was still found. This indicates that the proposed mechanism for vertical wire growth on [100] substrates, ${ }^{20}$ which is based on preventing the formation of an alloy between the $\mathrm{Au}$ particle and the substrate, is not valid under our growth conditions. In an additional experiment the sample was pre-annealed at $550{ }^{\circ} \mathrm{C}$ for $10 \mathrm{~min}$ before growth. This did not significantly affect the yield of vertical wires, supporting our conclusion. In Fig. 2(b) the yield of vertical wires is plotted as a function of the diameter. The highest fraction is obtained for $\mathrm{D}_{\mathrm{Au}}=50 \mathrm{~nm}$, while the fraction of tilted NWs is not affected by the diameter. The fraction of vertical NWs is also affected by the V/III ratio as shown in Figs. 2(c) and 2(d). In these graphs the yield is given for a varied $\mathrm{F}_{\mathrm{TMI}}$ (or $\mathrm{F}_{\mathrm{PH} 3}$ ) but a fixed $\mathrm{F}_{\mathrm{PH} 3}$ (or $\mathrm{F}_{\mathrm{TMI}}$ ). Below a critical total molar fraction
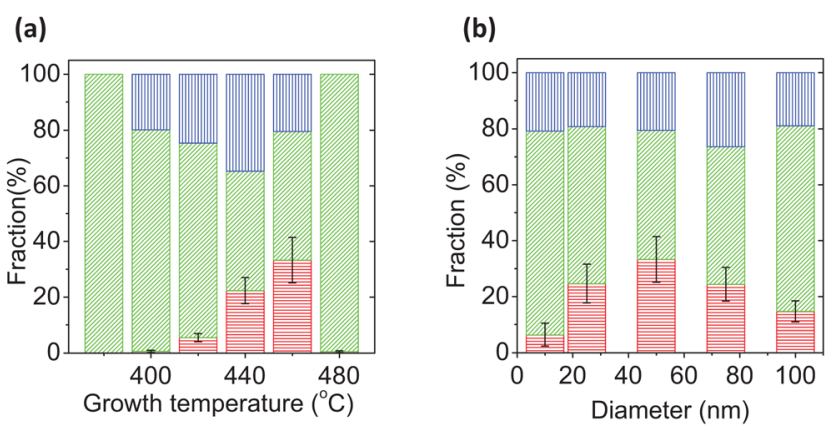

(c)

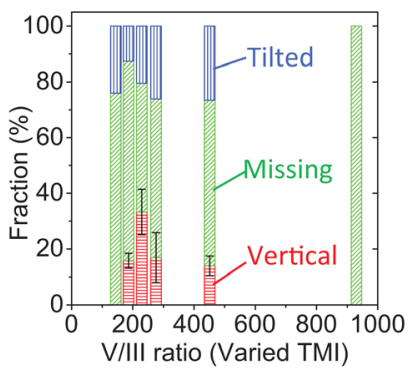

(d)

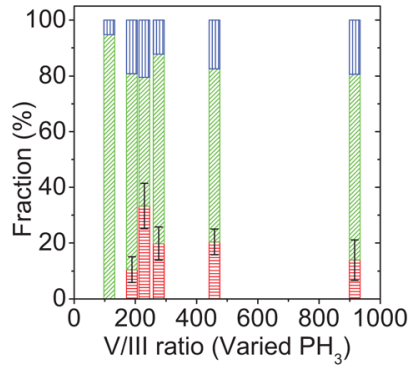

FIG. 2. (Color online) Histograms of vertical, tilted, and missing NW fractions varying with different parameters: (a) with $\mathrm{D}_{\mathrm{Au}}=50 \mathrm{~nm}, \mathrm{~V} / \mathrm{III}$ ratio $=229$, varying $\mathrm{T}$. (b) With $\mathrm{V} / \mathrm{III}$ ratio $=229, \mathrm{~T}=460^{\circ} \mathrm{C}$, varying $\mathrm{D}_{\mathrm{Au}}$. (c) $\mathrm{D}_{\mathrm{Au}}=50 \mathrm{~nm}, \mathrm{~T}=460^{\circ} \mathrm{C}$, molar fraction of $\mathrm{PH}_{3}\left(\mathrm{~F}_{\mathrm{PH} 3}\right)=5.5 \times 10^{-3}$, with varying $\mathrm{V} / \mathrm{III}$ ratio by changing $\mathrm{TMI}$ molar fraction $\left(\mathrm{F}_{\mathrm{TMI}}\right)$. (d) $\mathrm{D}_{\mathrm{Au}}=50 \mathrm{~nm}, \mathrm{~T}=460^{\circ} \mathrm{C}, \mathrm{F}_{\mathrm{TMI}}=3.8 \times 10^{-5}$, with varying $\mathrm{V} / \mathrm{III}$ ratio by changing $\mathrm{F}_{\mathrm{PH} 3}$. The error bars indicate the standard deviation of our measurements.

$\left(\mathrm{F}_{\mathrm{TMI}}=3.9 \times 10^{-5}\right.$ and $\left.\mathrm{F}_{\mathrm{PH} 3}=5.5 \times 10^{-3}\right)$, there are no vertical NWs grown. If it is decreased further, keeping the same V/III ratio, no NW growth is observed. Finally, it was found that the yield is independent of the wire-to-wire distance, indicating that the V/III ratio does not change with the wireto-wire distance under these growth conditions. In other words, the diffusion length of the precursors on the $\operatorname{InP}(100)$ is either much longer or shorter than the wire-to-wire distance used in this work. We note that all the samples were coated with a thin film of poly-L-lysine (PLL), which could change surface energies, and with that the shape of the droplet shape; ${ }^{24}$ without PLL coating, the vertical NW yield is reduced by $10 \%$.

In order to verify the NW crystalline structure, TEM studies were performed for ten NWs. Fig. 3(a) shows a bright field TEM image of a typical [100] InP NW deposited on a holey carbon film. The defect-free pure ZB crystal structure of the wire is clear from the high resolution TEM image in Fig. 3(b). Note that twin boundaries (parallel to $\{111\}$ lattice planes) are well recognizable both in [011] as well as in [001] zone-axis imaging and have not been observed here. The optical properties of single [100] wires are investigated by low-temperature micro-PL (Fig. 3(c)). At the lowest excitation power used here $\left(2.4 \mathrm{~W} / \mathrm{cm}^{-2}\right)$ a peak (II) at $1.415 \mathrm{eV}$ was observed, with a full width at half maximum (FWHM) of $2.3 \mathrm{meV}$. This peak is $5 \mathrm{meV}$ below the band-gap energy of zincblende InP (1.42 eV) and assigned to a donor-to-valence band transition. The peaks from $1.36-1.40 \mathrm{eV}$ are assigned to impurity-related emission. Note that no strong emission around $1.38 \mathrm{eV}$ is observed, typical for a conduction band-to-acceptor transition due to carbon impurity, even 


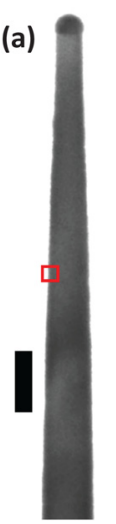

(b)
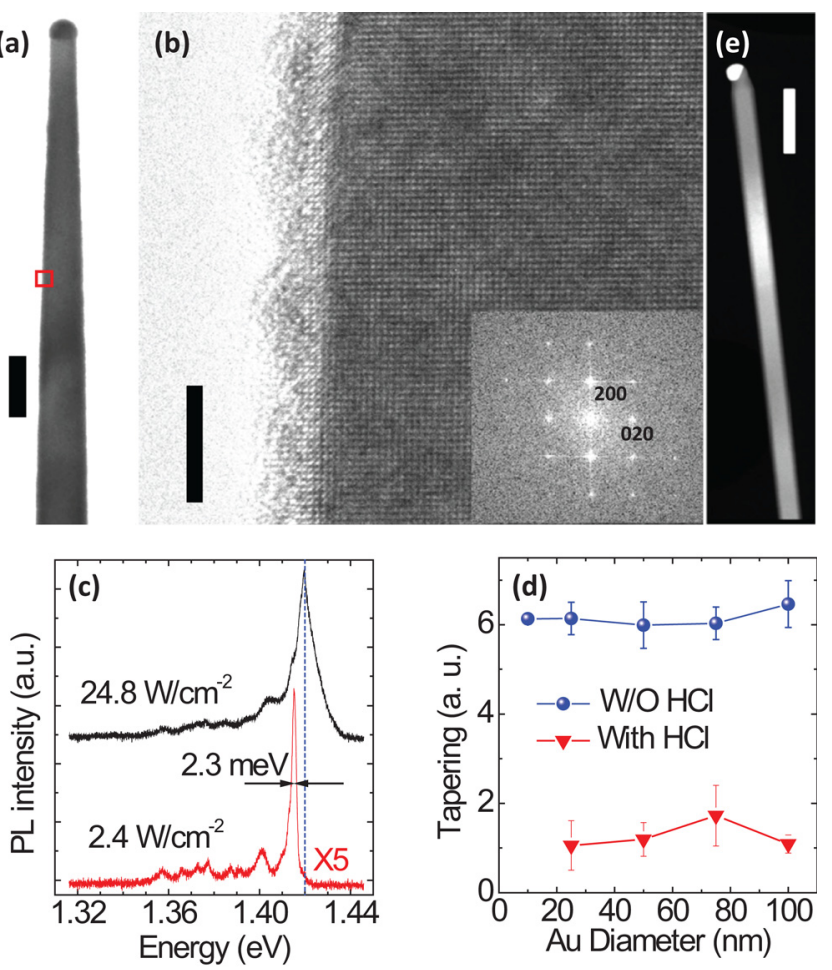

FIG. 3. (Color online) (a) Bright-field TEM image of a [100] InP NWs. (b) HRTEM image of the boxed area. The inset shows the Fourier transform of the HRTEM image, displaying a [001] zone axis pattern. (c) PL at $4 \mathrm{~K}$ from a single [100] InP NW transferred to an oxidized Si wafer. (d) Effect of $\mathrm{HCl}$ on InP NW tapering. (e) High angle annular dark field STEM image of a [100] InP NW grown with $\mathrm{HCl}$ at partial pressure $8.33 \times 10^{-4}$ mbar. The scale bar is $100 \mathrm{~nm}$ for (a),(e) and $5 \mathrm{~nm}$ for (b).

though the NWs are grown at a relatively low growth temperature $\left(460^{\circ} \mathrm{C}\right)$. With $24.8 \mathrm{~W} / \mathrm{cm}^{-2}$ excitation power, the band-gap related PL of the same NW is at $1.42 \mathrm{eV}$.

Finally, in order to reduce undesired lateral growth and realize uniformity along the [111] direction, in situ $\mathrm{HCl}$ etching is used as shown for [111] NW. ${ }^{23} \mathrm{HCl}$ is simultaneously switched on and off with TMI. Fig. 3(d) shows that all NWs grown without $\mathrm{HCl}$ are tapered, independently of the diameter (tapering is defined as the difference between the bottom and top NW diameter divided by its length: $\left.\left(D_{b}-D_{t}\right) / L\right)$. Nearly untapered wires are obtained by using an $\mathrm{HCl}$ partial pressure of $8.33 \times 10^{-4} \mathrm{mbar}$, as can be seen in Fig. 3(e).

As already visible from SEM studies, NW growth without $\mathrm{HCl}$ yields $\{100\}$ facets upon lateral growth. On the contrary, NW growth with $\mathrm{HCl}$ yields an octagonal shape formed by four $\{110\}$ and four $\{100\}$ side facets, as confirmed by a more detailed TEM study. A detailed analysis of the effect of $\mathrm{HCl}$ will be presented elsewhere.

In conclusion, [100] InP NWs with more than $50 \%$ yield have been fabricated with optimized growth parameters on
(100) InP substrates grown by MOVPE. The NW's crosssectional shape can be tuned by using $\mathrm{HCl}$. These defect-free pure ZB wires have high optical quality as concluded from the sharp emission peak $(F W H M=2.3 \mathrm{meV})$ and are a promising platform for the integration of InAsP quantum dots. $^{25}$ It allows to precisely tuning the cross-sectional shape and length to tailor and minimize the fine structure splitting. $^{26}$

${ }^{1}$ X. F. Duan, Y. Huang, Y. Cui, J. F. Wang, and C. M. Lieber, Nature 409, 66 (2001).

${ }^{2}$ J. Wang, M. S. Gudiksen, X. Duan, Y. Cui, and C. M. Lieber, Science 24, 1455 (2001).

${ }^{3}$ Y. Ding, J. Motohisa, B. Hua, S. Hara, and T. Fukui, Nano Lett. 7, 3598 (2007).

${ }^{4}$ R. Yan, D. Gargas, and P. Yang, Nat. Photon. 3, 569 (2009).

${ }^{5}$ H. Goto, K. Nosaki, K. Tomioka, S. Hara, K. Hiruma, J. Motohisa, and T. Fukui, Appl. Phys. Express 2, 035004 (2009).

${ }^{6}$ M. T. Borgström, J. Wallentin, M. Heurlin, S. Fält, P. Wickert, J. Leene, M. H. Magnusson, K. Deppert, and L. Samuelson, IEEE J. Sel. Top. Quantum Electron. 17, 1050 (2010).

${ }^{7}$ M. T. Björk, B. J. Ohlsson, C. Thelander, A. I. Persson, K. Deppert, L. R. Wallenberg, and L. Samuelson, Appl. Phys. Lett. 81, 4458 (2002).

${ }^{8}$ E. D. Minot, F. Kelkensberg, M. van Kouwen, J. A. van Dam, L. P. Kouwenhoven, V. Zwiller, M. T. Borgström, O. Wunnicke, M. A. Verheijen, and E. P. A. M. Bakkers, Nano Lett. 7, 367 (2007).

${ }^{9}$ P. Mohan, J. Motohisa, and T. Fukui, Appl. Phys. Lett. 88, 133105 (2006).

${ }^{10}$ S. Bhunia, T. Kawamura, S. Fujikawa, H. Nakashima, K. Furukawa, K. Torimitsu, and Y. Watanabe, Thin Solid Films 464, 244 (2004).

${ }^{11}$ Q. Xiong, J. Wang, and P. C. Eklund, Nano Lett. 6(12), 2736 (2006).

${ }^{12}$ R. E. Algra, M. A. Verheijen, M. T. Borgström, L. Feiner, G. Immink, W. J. P. van Enckevort, E. Vlieg, and E. P. A. M. Bakkers, Nature 456, 369 (2008).

${ }^{13}$ J. Bao, D. C. Bell, F. Capasso, J. B. Wagner, T. Mårtensson, J. Trägårdh, and L. Samuelson, Nano Lett. 8, 836 (2008).

${ }^{14}$ K. Ikejiri, Y. Kitauchi, K. Tomioka, J. Motohisa, and T. Fukui, Nano Lett. 11(10), 4314 (2011).

${ }^{15}$ N. Akopian, G. Patriarche, L. Liu, J. C. Harmand, and V. Zwiller, Nano Lett. 10, 1198 (2010).

${ }^{16}$ Z. Ikonic, G. P. Srivastava, and J. C. Inkson, Phys. Rev. B 52, 14078 (1995).

${ }^{17}$ M. D. Schroer and J. R. Petta, Nano Lett. 10, 1618 (2010).

${ }^{18}$ S. A. Dayeh, D. Susac, K. L. Kavanagh, E. T. Yu, and D. Wang, Adv. Funct. Mater. 19, 2102 (2009).

${ }^{19}$ C. Thelander, P. Caroff, S. Plissard, A. W. Dey, and K. A. Dick, Nano Lett. 11, 2424 (2011).

${ }^{20}$ U. Krishnamachari, M. Borgstrom, B. J. Ohlsson, N. Panev, L. Samuelson, W. Seifert, M. W. Larsson, and L. R. Wallenberg, Appl. Phys. Lett. 85, 2077 (2004).

${ }^{21}$ R. S. Wagner and W. C. Ellis, Appl. Phys. Lett. 4, 89 (1964).

${ }^{22}$ A. Pierret, M. Hocevar, S. L Diedenhofen, R. E Algra, E. Vlieg, E. C. Timmering, M. A. Verschuuren, G. W. G. Immink, M. A Verheijen, and E. P. A. M. Bakkers, Nanotechnology 21, 065305 (2010).

${ }^{23}$ M. T. Borgström, J. Wallentin, J. Trägårdh, P. Ramvall, M. Ek, L. R. Wallenberg, L. Samuelson, and K. Deppert, Nano Res. 3, 264 (2010).

${ }^{24}$ A. Mikkelsen, J. Eriksson, E. Lundgren, J. N. Andersen, J. Weissenrieder, and W. Seifert, Nanotechnology 16, 2354 (2005).

${ }^{25}$ M. H. M. van Weert, N. Akopian, U. Perinetti, M. P. van Kouwen, R. E. Algra, M. A. Verheijen, E. P. A. M. Bakkers, L. P. Kouwenhoven, and V. Zwiller, Nano Lett. 9, 1989 (2009).

${ }^{26}$ R. Singh and G. Bester, Phys. Rev. Lett. 103, 063601 (2009). 